\title{
Association of Higher Maternal Serum Fluoride with Adverse Fetal Outcomes
}

\author{
Gurumurthy Sastry $\mathrm{M}^{\star}$, Shruti Mohanty**, Aparna Varma Bhongir*, A. K. Mishra ${ }^{\dagger}$, Pragna Rao ${ }^{\dagger \dagger}$ \\ *Dept. of Biochemistry, Mediciti Institute of Medical Sciences, SHARE India, Ghanpur, Medchal Mandal, RR Dist.-501401, AP, India. \\ ${ }^{* *}$ Dept. of Biochemistry, Kamineni Institute of Medical Sciences, Sreepuram, Narketpally (M), Nalgonda, AP, India. \\ ${ }^{\dagger}$ Dept. of Community Medicine, Mediciti Institute of Medical Sciences, SHARE India, Ghanpur, Medchal Mandal, RR Dist.-501401, AP, India. \\ ${ }^{+}$Dept of Biochemistry, Kasturba Medical College, Manipal, India.
}

\section{A B STRACT}

Background: Despite prevalence of fluorosis in India, previous studies did not emphasize on the effect of maternal fluorosis on fetal outcomes. Objectives: To study the associations of higher maternal serum Fluoride (F) with low birth weight and poor APGAR count. Methods: One hundred and eight apparently healthy pregnant women aged 17-36 years were included in the study. Samples collected were maternal and cord blood, placenta and drinking and ground water. The samples were processed and analyzed for Fluoride. Fetal gestational age was measured on ultrasound scan and the birth weight of the baby on a digital scale. Fifth minute APGAR score was measured. Results: A significant negative correlation was found for maternal serum $\mathrm{F}$ vs Birth weight, Gestational Age and APGAR score. Significant negative correlations were also found for cord serum $\mathrm{F}$ vs Birth Weight, Gestational Age and APGAR score. Fairly negative correlations were also found for birth weight, APGAR score and Gestational age compared to Fluoride concentrations in maternal surface of placenta, fetal surface of placenta and marginal side of the placenta. However, significant positive correlations were observed when Gestational age was compared with Birth weight and APGAR score. When the maternal serum $\mathrm{F}$ was greater than $1 \mathrm{ppm}$, there was 10.58 times higher risk for low birth weight, 8.65 times higher risk for preterm delivery and 3.8 times higher risk for low APGAR score. When the cord serum F was greater than $0.22 \mathrm{ppm}$, there was 2.76 times higher risk for low birth weight, 4.6 times higher risk for preterm delivery and 2.5 times higher risk for low APGAR score. Conclusion: With increased serum $F$ in the mother, there is an inclination towards pre term delivery, low birth weight and poor APGAR count.

Key words: APGAR score, Placenta, Low Birth weight, Endemic fluorosis, Gestational age.

\section{INTRODUCTION}

Fluorosis is a disease caused by deposition of fluorides in the hard and soft tissues of the body, manifesting as dental or skeletal fluorosis or both, resulting from higher intake of fluoride (F) above $1.5 \mathrm{ppm}$ per day. ${ }^{1,2}$ Studies on transplacental $F$ transport suggest that $F$ passes through placenta to the fetus. Few studies also reported adverse fetal outcomes and higher incidence of trisomy 21 with higher maternal $\mathrm{F}^{3}$ However, there are hardly few studies relating maternal F, birth weight and APGAR score. Hence, the present study, done in Nalgonda district of Andhra Pradesh, India, an endemic fluorosis area aims to find if babies born to mothers with higher serum $F$ have low birth weight and poor APGAR count.

Address for correspondence:

Phone No.: +91-8418-256 201 (extn: 248); +91-97006-04023

E-mail: sastrymgurumurthy@gmail.com

DOI: 10.5530/ijmedph.2.2011.4

\section{OBJECTIVES}

To study the associations of higher maternal serum $\mathrm{F}$ with low birth weight and poor APGAR count in endemic fluorosis region.

\section{MATERIALS AND METHODS}

Selection of subjects: The study included one hundred and eight pregnant women at term aged 17 to 36 yrs residing in Nalgonda District, Andhra Pradesh, India. Reported pregnancy was confirmed on an ultra sound scan. Only those women who were pregnant for not more than 14 weeks at the time of scan were recruited. One hundred and twenty women were initially recruited in the study; but only 108 had delivery at our hospital. The women were under regular antenatal care of the Obstetricians in the Department of Obstetrics at Kamineni Institute of Medical Sciences, Nalgonda. All the women volunteered to participate in the study and gave their consent for the same. This study was 
conducted with the approval of the institutional ethics committee during June 2009 to April 2010.

\section{Samples}

Blood: $3 \mathrm{ml}$ of maternal venous, and cord blood were drawn into disposable plain polystyrene tubes. Maternal blood was drawn during first hour of delivery and cord blood was collected at birth. Placenta was collected immediately after expulsion under sterile conditions and was carried to laboratory in an ice pack. Laboratory analyses were conducted in the Department of Biochemistry of Kamineni Institute of Medical Sciences. The samples were collected, handled and transported to the lab according to the guidelines given by clinical and laboratory standards institute/NCCLS (National Clinical Chemistry Laboratory Standards). ${ }^{4,5}$ The blood samples were centrifuged at $3000 \mathrm{rpm}$ for 10 minutes and the serum was immediately analyzed for $\mathrm{F}$.

Placenta: Placenta was collected immediately after expulsion under sterile conditions and was carried to lab in an ice pack. The placenta was divided into a central part and marginal part. The central part was further subdivided into maternal and fetal surfaces. $10 \mathrm{gm}$ of tissue was cut from each part. These tissues were homogenized immediately using $10 \mathrm{~mL}$ normal saline at 100,000 rpm for $45 \mathrm{~min}$ in a pressure driven tissue homogenizer. Precautions were taken according to those given in the manual of the tissue homogenizer. Briefly, the speed of the homogenizer was not increased or decreased abruptly. It is done gradually; homogenization was always done in ice pack as it generates heat. The homogenization procedure developed was standardized and validated against other procedures. ${ }^{6,7}$ The tissue extract was processed immediately for $\mathrm{F}$ analysis. The homogenate was transferred into a centrifuge tube and centrifuged at $3000 \mathrm{rpm}$ for $5 \mathrm{~min}$. Now the total volume (Volume of buffer + volume of tissue fluid) was noted and the approximate dilution of the tissue fluid was calculated. The tissue extract was processed immediately for fluoride analysis and the results obtained were multiplied with appropriate dilution factor to calculate the actual values of fluoride.

Water: Drinking and ground water was brought by the family members of the subjects on request for $\mathrm{F}$ analysis since water was the major source of fluoride intake.

\section{METHODS}

1. F Assay: F was analyzed by ion selective procedure at $\mathrm{pH} 5.0$ adjusted with TISAB (Total Ionic Strength Adjustment Buffer) III buffer using Eutech Epoxy Body Electrode. The instrument was calibrated and standardized using four solutions having F concentrations of $0.01 \mathrm{ppm}$, $0.1 \mathrm{ppm}, 1 \mathrm{ppm}$ and $10 \mathrm{ppm}$. The standards were run before analysis of each sample and the electrode was calibrated periodically. Other measures were followed according to those given in the instrument manual. Briefly, all solutions were analyzed in plastic ware and not glass ware; the electrode was calibrated every day, and samples were processed after checking the controls for each batch of ten samples.

2. Birth Weight: Following delivery, the baby was carefully weighed, following necessary precautions, on a digital scale (Seca 354/364) which has sensitivity of $\pm 10 \mathrm{gm}$. The scale was calibrated periodically against standard weights and the calibration was rechecked. Babies weighing $2500 \mathrm{gm}$ and above were considered normal while those weighing $<2500$ gm were considered low birth weight.

3. APGAR Score: The APGAR score is determined by evaluating the newborn baby on five simple criteria on a scale from zero to two, then summing up the five values thus obtained. The resulting APGAR score ranges from zero to 10. The five criteria (Appearance, Pulse, Grimace, Activity, Respiration) are used as a mnemonic learning aid. The test is generally done at one and five minutes after birth, and may be repeated later if the score is and remains low. Scores 3 and below are generally regarded as critically low, 4 to 6 fairly low, and 7 to 10 generally normal. However, for the present study, fifth minute APGAR score is considered8, 9.

APGAR score is calculated from the score chart depicted in table 1.

4. Gestational Age: Gestational age was estimated by fetal biometry on an ultra sound scan. WHO guidelines were followed for the scan. ${ }^{10}$ The subject was given four to five glasses of water and instructed not to micturate till the scan was done. The bladder was not filled with a urethral

\begin{tabular}{|c|c|c|c|c|}
\hline & Score of 0 & Score of 1 & Score of 2 & Score of the baby \\
\hline Appearance & blue or pale all over & $\begin{array}{l}\text { blue at extremities body } \\
\text { pink (acrocyanosis) }\end{array}$ & $\begin{array}{l}\text { No cyanosis- pink } \\
\text { body and extremities }\end{array}$ & \\
\hline Pulse Rate & Absent & $<100$ & $\geq 100$ & \\
\hline Grimance (Reflex irritability) & $\begin{array}{l}\text { no response to } \\
\text { stimulation }\end{array}$ & $\begin{array}{l}\text { grimace/feeble cry when } \\
\text { stimulated }\end{array}$ & $\begin{array}{l}\text { cry or pull away when } \\
\text { stimulated }\end{array}$ & \\
\hline Activity (muscle tone) & none & Some flexion & $\begin{array}{l}\text { flexed arms and legs } \\
\text { that resist extension }\end{array}$ & \\
\hline Respiration (Breathing) & absent & weak, irregular, gasping & strong, lusty cry & \\
\hline
\end{tabular}


catheter to avoid the possible risk of infection. The patient was asked to lie supine comfortably and a coupling agent was applied liberally to the lower abdomen. A $3.5 \mathrm{MHz}$ transducer was positioned longitudinally over the full bladder and the gain was adjusted to produce the best image. Because of the regional cultural practices, most women do not report in their first trimester and hence most women visit the OPD usually after $12^{\text {th }}$ week. Hence Biparietal Diameter (BPD), the distance between the parietal eminences on either side of the skull, was considered to estimate gestational age of the fetus, since BPD is the most reliable method of estimating gestational age between $12^{\text {th }}$ and $26^{\text {th }}$ weeks of pregnancy. "Leading- edge- to- leading- edge" technique was used to measure BPD. Using scan at different angles, the transverse section was recognized when the shape of the fetal skull was ovoid and the midline echo from the falx cerebri was interrupted by the cavum septum pellicidi and the thalami. When this plane was found, the gain on the ultrasound unit was reduced and measurements were made from the outer table of the proximal skull to the inner table of the distal skull. The soft tissues over the skull were not included. The gestational age was determined from BPD to within approximately nine days using biometric tables that are appropriate to the local population.

Data Analysis: The data was processed in MS EXCEL and analysis was carried out using SPSS (1 $7^{\text {th }}$ version). The results were statistically analyzed by the Student's t-test and by Pearson's correlation coefficient. Cutoffs were taken using chi square test and risk estimates by odds ratio. A two tailed probability value of $<0.05$ and an odds ratio $>1$ were taken as indicating significance.

\section{RESULTS}

All the subjects in the study were resident of Nalgonda district (an endemic fluorosis area). These subjects use Government supplied Krishna River water for drinking and ground water for house hold activities like washing, cleaning etc, and also for cooking. Ground and drinking water samples were provided by all the participants $(n=108)$ and the F levels in the water samples were $10.64 \pm 2.09$ ppm and $4.4 \pm 1.6 \mathrm{ppm}$ respectively. These subjects depend on locally grown food crops and vegetables for their daily requirements. The water sources suggest higher intake of $\mathrm{F}$ than the maximum, $1.5 \mathrm{ppm}$, recommended by WHO and Indian Standard Code for Drinking Water., The demographic detail of the subjects is presented in table 2 .

F content of the water sources and details of the neonates are presented in tables 3 and 4 .

$F$ values in the samples are presented in Table 5.
A significant negative correlation was found for maternal serum F vs Birth weight $(r=-0.52 ; p<0.0001)$, Gestational Age $(r=-0.56 ; p<0.0001)$ and APGAR score $(r=-0.65$; $p<0.0001)$. Significant negative correlations were also found for cord serum F vs Birth Weight $(r=-0.41 ; p<0.0001)$, Gestational Age $(r=-0.35 ; p<0.0001)$ and APGAR score $(r=-0.41 ; p<0.0001)$. Fairly negative correlations were also found for birth weight, APGAR score and Gestational age compared to Fluoride concentrations in maternal surface of placenta $(r=-0.51, p<0.0001 ; r=-0.53, p<0.0001$ and $r=-0.46, p<0.0001$ respectively $)$, fetal surface of placenta $(r=-0.41, p<0.0001 ; r=-0.47, p<0.0001$ and $r=-0.34, p<0.0001$ respectively) and on the marginal side $(r=-0.43, p<0.0001 ; r=-0.47, p<0.0001$ and $r=-0.38$, $p<0.0001$ respectively). However, significant positive correlations were observed when Gestational age was compared with Birth weight $(r=+0.51 ; p<0.0001)$ and APGAR score $(r=+0.48 ; p<0.0001)$. These findings suggest that with increased serum $F$ in the mother, there is an inclination towards pre term delivery, low birth weight and poor APGAR count.

From the existing studies no reference could be obtained regarding the minimum level of maternal serum or cord serum $F$ levels that have adverse outcome on the baby in endemic fluorosis area, ${ }^{12}$ an attempt was made by processing the data to obtain Odds Ratio and Pearson's Chi Square

\begin{tabular}{lcc}
\multicolumn{3}{l}{ Table 2: Demographics of subjects $(\boldsymbol{n}=\mathbf{1 0 8 )}$} \\
\hline \multicolumn{1}{|c}{ Parameters } & Range & Mean \pm SD \\
\hline $\begin{array}{l}\text { Age group (Years) } \\
\text { Weight (Kgs.) }\end{array}$ & $17-36$ & $26.4 \pm 5.2$ \\
Gravida $(\boldsymbol{n})$ & $40-60$ & $48.0 \pm 5.2$ \\
Parity $(\boldsymbol{n})$ & 1 to 4 \\
\hline \multicolumn{3}{c}{ Type of delivery } \\
\hline $\begin{array}{l}\text { 1. Vaginal } \\
\text { 2. Lower Segment Caesarean Section }\end{array}$ \\
\hline
\end{tabular}

\begin{tabular}{lcc} 
Table 3: F Content in Water sources \\
\hline & Ground Water F (ppm) & Tap Water F (ppm) \\
\hline Mean & 10.64 & 4.4 \\
SD & 2.09 & 1.6 \\
Min & 3.6 & 0.91 \\
Max & 16 & 5.2 \\
Median & 5.8 & 2.2 \\
\hline
\end{tabular}

Table 4: Details of the Neonates

\begin{tabular}{lccc}
\hline & $\begin{array}{c}\text { Birth Weight } \\
(\mathbf{k g})\end{array}$ & $\begin{array}{c}\text { Gestational Age } \\
\text { (days) }\end{array}$ & APGAR Score \\
\hline Mean & 2.51 & 262 & 7.6 \\
SD & 0.27 & 4.4 & 0.97 \\
Min & 1.9 & 253 & 6 \\
Max & 3.1 & 270 & 9 \\
Median & 2.5 & 262 & 8 \\
\hline
\end{tabular}


value and $1 \mathrm{ppm}$ for maternal serum Fluoride and $0.22 \mathrm{ppm}$ for cord $\mathrm{F}$ was considered cut off in our study.

\section{Maternal F vs Fetal outcomes}

The gestational age $\left(\chi^{2}=16.8 ; p<0.0001\right)$, APGAR score $\left(\chi^{2}=4.37 ; p=0.037\right)$ and birth weight $\left(\chi^{2}=29.8 ; p<0.0001\right)$ of the baby were significantly associated with maternal serum $F$, when $1 \mathrm{ppm}$ was considered as cut off. It was also seen that when the maternal serum $F$ was greater than $1 \mathrm{ppm}$, there was 10.58 times higher risk for low birth weight, 8.65 times higher risk for preterm delivery and 3.8 times higher risk for low APGAR score. These findings were summarised in table 6 .

\section{Cord F vs Fetal outcomes}

Gestational age of the baby $\left(\chi^{2}=11.37 ; p<0.001\right)$ is significantly associated with Cord $\mathrm{F}$ while birth weight $\left(\chi^{2}=6.48 ; p=0.11\right)$ and APGAR score $\left(\chi^{2}=2.64 ; p=0.1\right)$ did not associate significantly. When the cord serum $\mathrm{F}$ was greater than $0.22 \mathrm{ppm}$, there was 2.76 times higher risk for low birth weight, 4.6 times higher risk for preterm delivery and 2.5 times higher risk for low APGAR score. These findings were summarised in table 7 .

\section{DISCUSSION}

There is wide variation with some correlation between fluoride concentration in maternal serum and cord blood, indicating that fluoride readily crosses the placenta. In general, average cord blood concentrations are approximately $60 \%$ of maternal serum concentrations, with proportionally lesser amounts present as higher maternal serum concentrations. ${ }^{11,12,13,14}$ Therefore, potential toxicity to the developing embryo and fetus in the setting of high maternal ingestion of fluoride has been a concern, evaluated in both animal and humans. Jendryczko A etal15 studied the associations of mineral components of human placenta with birth weight and infant head circumference and found that significant negative correlations were ascertained between the content of $\mathrm{Pb}$, $\mathrm{Cd}, \mathrm{F}, \mathrm{Hg}$ and the birth weight. We also found fairly significant negative correlations between birth weight and F content in different regions of placenta. Makrozynski and Machoy16 estimated $\mathrm{F}$ content of fetal bone as an indication of prenatal $\mathrm{F}$ exposure and found statistically significant negative correlations between the fetal age and F contents in the shaft and in the metaphyseal part of bones in sixty four fetuses with an intra uterine life ranging between 14-36 weeks.

Table 5: Distribution of $\mathrm{F}$ in different regions of placenta, maternal and cord blood sera.

\begin{tabular}{|c|c|c|c|c|c|}
\hline \multirow[t]{3}{*}{ Fluoride (ppm) } & \multicolumn{5}{|c|}{ SAMPLES } \\
\hline & \multirow[t]{2}{*}{ Maternal Serum } & \multicolumn{3}{|c|}{ PLACENTA } & \multirow[t]{2}{*}{ Cord Serum } \\
\hline & & Maternal surface & Fetal Surface & Periphery & \\
\hline Mean & 1.21 & 1.59 & 1.41 & 2.38 & 0.39 \\
\hline SD & 0.79 & 0.78 & 0.79 & 1.46 & 0.5 \\
\hline Min & 0.04 & 0.66 & 0.13 & 0.13 & 0.01 \\
\hline Max & 4.4 & 3.23 & 2.72 & 6.6 & 2.6 \\
\hline Median & 1.17 & 1.41 & 1.29 & 2.3 & 0.22 \\
\hline
\end{tabular}

\begin{tabular}{|c|c|c|c|c|c|c|}
\hline & & $\begin{array}{l}\text { Maternal } \\
\text { F > 1 ppm } \\
(n=62)\end{array}$ & $\begin{array}{l}\text { Maternal } \\
\text { F } \leq 1 \mathrm{ppm} \\
(n=46)\end{array}$ & $\begin{array}{c}\text { Total } \\
(n=108)\end{array}$ & $\chi^{2}(p)$ & $\begin{array}{c}\text { Relative Risk } \\
\text { (Lower-Upper at 95\% } \\
\text { Confidence Interval) }\end{array}$ \\
\hline \multirow[t]{2}{*}{ Birth Weight } & Low & 50 & 13 & 63 & $29.8(p<0.0001)$ & $10.58(4.3-25.99)$ \\
\hline & Normal & 12 & 33 & 45 & & \\
\hline \multirow[t]{2}{*}{ Gestational Age } & Preterm & 28 & 4 & 32 & $16.8(p<0.0001)$ & $8.65(2.76-27.1)$ \\
\hline & Term & 34 & 42 & 76 & & \\
\hline \multirow[t]{2}{*}{ APGAR score } & Low & 13 & 3 & 16 & $4.37(p<0.0001)$ & $3.8(1.02-14.24)$ \\
\hline & Normal & 49 & 43 & 92 & & \\
\hline
\end{tabular}

\begin{tabular}{|c|c|c|c|c|c|c|}
\hline & & $\begin{array}{c}\text { Cord } \\
\mathrm{F}>0.22 \mathrm{ppm} \\
(n=54)\end{array}$ & $\begin{array}{c}\text { Cord } \\
\mathrm{F} \leq 0.22 \mathrm{ppm} \\
(n=54)\end{array}$ & $\begin{array}{c}\text { Total } \\
(n=108)\end{array}$ & $\chi^{2}(p)$ & $\begin{array}{c}\text { Relative Risk } \\
\text { (Lower-Upper at } 95 \% \\
\text { Confidence Interval) }\end{array}$ \\
\hline \multirow[t]{2}{*}{ Birth Weight } & Low & 38 & 25 & 63 & $6.48(p=0.11)$ & $2.76(1.26-6.1)$ \\
\hline & Normal & 16 & 29 & 45 & & \\
\hline \multirow[t]{2}{*}{ Gestational Age } & Preterm & 24 & 8 & 32 & $11.37(p<0.001)$ & $4.6(1.83-11.57)$ \\
\hline & Term & 30 & 46 & 76 & & \\
\hline \multirow[t]{2}{*}{ APGAR score } & Low & 11 & 5 & 16 & $2.64(p=0.1)$ & $2.5(10.81-7.79)$ \\
\hline & Normal & 43 & 49 & 92 & & \\
\hline
\end{tabular}


However, we estimated the cord serum $\mathrm{F}$ as an indication of prenatal $\mathrm{F}$ exposure and found significant negative correlation with Gestational age of the fetus and also with other fetal outcomes like APGAR score and birth weight.

Apelberg etal17 studied maternal and cord serum concentrations of Perfluoro compounds in people exposed to $\mathrm{F}$ in plastic industry in relation to weight and size at birth. Positive association was observed between Perfluoro compounds and Gestational age which was statistically not significant and which diminished with adjustment for key predictors of gestational age; after adjusting for gestational age, these chemicals were negatively associated with birth weight $(p<0.05)$. In a similar Japanese study18 done recently, similar findings were reported. Though the sources of $\mathrm{F}$ exposure in the present study differ from those cited afore, we also found a negative association of maternal and cord blood serum $\mathrm{F}$ with fetal outcomes.

Supporting evidence with a plausible hypothesis was given in a recent study done by AK Susheela19. They found in a study group ( $n=205$; on relatively $\mathrm{F}$ free food and water as compared to a control group $(n=115)$, the incidence of preterm deliveries was reduced by four times and low birth weight babies by two times. This study also reports that Iron and Folate supplementations to the pregnant women reduce the risk of low birth weight provided, they are accompanied by good nutrition and reduced F intake. Further, we found that when maternal serum $F$ levels were above $1 \mathrm{ppm}$ there was higher relative risk for adverse fetal outcomes. However, the relative risk was statistically significant only for Gestational age when cord serum $F$ was above $0.22 \mathrm{ppm}$. This may be in part due to very low cord serum $\mathrm{F}$ levels which in turn may be due to sequestering of large amounts of $\mathrm{F}$ in placenta. However these cut offs may be established only after further studies that involve larger sample size.

\section{ACKNOWLEDGMENTS}

Authors are thankful to Kamineni Education Society for constant encouragement and funding for research; Patients of the study and their family members for their support and consent; Ms. Subhashini, Nursing Incharge, Dept. of Obstetrics and Gynecology, KIMS, for her valuable help to collect samples.

\section{REFERENCES}

1. WHO Guidelines for Drinking Water Equality, World Health Organisation, Geneva, 1984, 2:249.

2. BIS: 10500 , "Indian Standard code for drinking water", BIS, INDIA, 1983.

3. Whiting, P., M. MacDonagh, and J. Kleijnen. Association of Down's syndrome and water fluoride level: A systematic review of the evidence. BMC public health 2001; 1 (1):6.

4. Procedures for the collection of diagnostic blood specimens by venipuncture: Approved standard. $4^{\text {th }}$ ed. Wayne PA: National committee for Clinical Laboratory Standards, 1998.

5. Procedures for handling and transport of domestic diagnostic specimens and etiologic agents: Approved standard. $3^{\text {rd }}$ ed. Wayne PA: National committee for Clinical Laboratory Standards, 1994

6. McArdle $\mathrm{HJ}$, Douglas AJ \& Morgan $\mathrm{EH}$. Transferrin binding by microvillar vesicles isolated from rat placenta. Placenta, 1984; 5:131-138.

7. Angela M Finch, Li G Yang, Margaret O Nwagwu, Kenneth R Page, Harry $\mathrm{J}$ McArdle and Cheryl J Ashworth. Placental transport of leucine in a porcine model of low birth weight. Reproduction 2004; 128:229-35.

8. Apgar, Virginia."A proposal for a new method of evaluation of the newborn infant". Curr. Res. Anesth. Analg, 1953; 32 (4):260-267.

9. Casey BM; Mclntire DD, Leveno KJ. "The continuing value of the Apgar score for the assessment of newborn infants". N Engl J Med, 2001 Feb; 344 (7):467-471.

10. P.E.S. Palmer. Obstetrics, In: Manual of diagnostic ultrasound. WHO, Geneva; 2007.

11. Gurumurthy Sastry M, Shruti Mohanty, Pragna Rao. Role of placenta to combat fluorosis (in fetus) in endemic fluorosis area. National Journal of Integrated Research in Medicine, 2010; 1(4):16-19.

12. Gupta S, Seth AK, Gupta A et al. Transplacental passage of fluorides. J Pediatr, 1993; 1233(1):139-41.

13. Malhotra A, Tewar A, Chawla HS et al. Placental transfer of Fluoride in pregnant women consuming optimum Fluoride in drinking water. $J$ Indian Soc Pedod Prev Dent, 1993; 11 (1):1-3.

14. Shimonovitz S, Patz D, Ever- Hadani $P$ et al. Umbilical cord fluoride serum levels may not reflect fetal fluoride status. J Perinat Med, 1995; 23(4):279-82.

15. Jendryczko A, Tomala J, Szpyrka G et al. Mineral components of human placenta, birth weight and infant head circumference. Ginekol Pol, 1995; 66(5):267-71.

16. Mokrzynski, S., and Z. Machoy. Fluoride incorporation into fetal bone. Fluoride, 1994; 27(3):151-154.

17. Apelberg, Witter, Herbstman, Calafat, Halden, Needham, Goldman Cord Serum Concentrations of Perfluorooctane Sulfonate (PFOS) and Perfluorooctanate (PFOA) in Relation to Weight and Size at Birth. Environmental Health perspectives, 2007; 115 (11):1670-1676.

18. Noriaki Washino, Yasuaki Saijo, Seiko Sasaki, Shizue Kato, Susumu Ban, Kanae Konishi, Rie Ito, Ayako Nakata, Yusuke Iwasaki, Koichi Saito, Hiroyuki Nakazawa, and Reiko Kishi. Correlations between prenatal exposure to perfluoridated chemicals and reduced fetal growth. Environmental Health perspectives, 2009; 117 (4):660-667.

19. A. K. Susheela, N. K. Mondal, Rashmi Gupta, Kamla Ganesh, Shashikant Brahmankar, Shammi Bhasin, and G. Gupta. Effective interventional approach to control anemia in pregnant women. Current Science, 2010; 98(10):1320-1330. 